
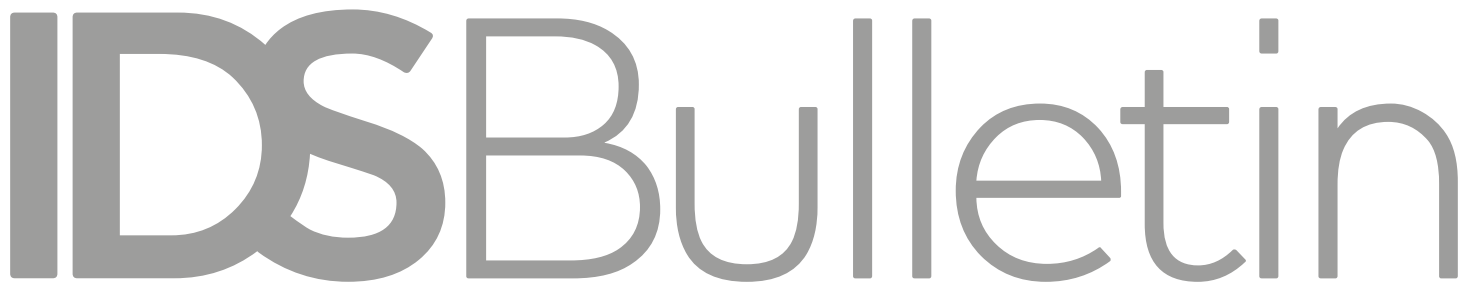

Transforming Developm

Volume 47 | Number 1A | March 2016

\title{
CONNECTING \\ PERSPECTIVES \\ ON WOMEN'S \\ EMPOWERMENT
}

\section{Editors Deepta Chopra and Catherine Müller}

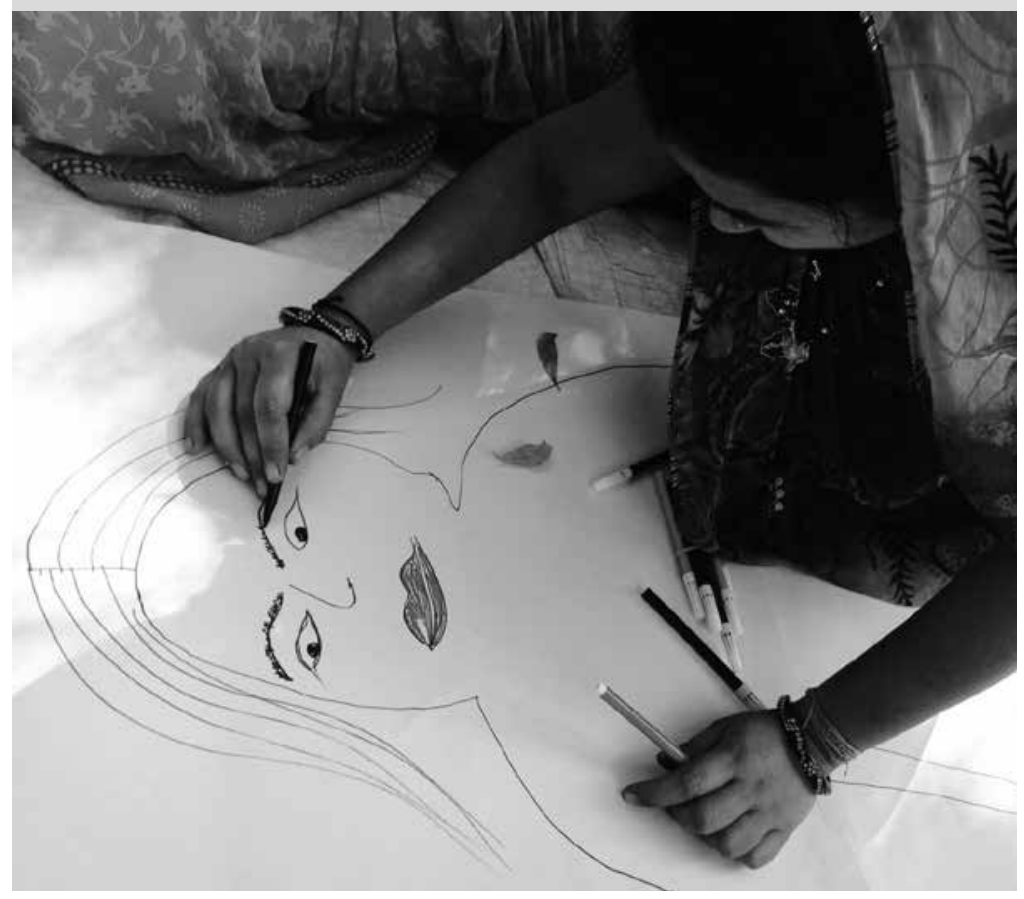




\section{Contents}

Introduction: Connecting Perspectives on Women's Empowerment

Deepta Chopra and Catherine Müller $\quad$ Article first published March 2016, IDSB47.1A

Liberal vs. Liberating Empowerment: A Latin American Feminist Perspective on Conceptualising Women's Empowerment

Cecília M.B. Sardenberg

Article first published December 2008, IDSB39.6

From Rags to Riches: Looking at Poverty from a Gender Perspective

Shahra Razavi

Article first published July 1997, IDSB28.3

Editorial: Tactics and Trade-Offs: Revisiting the Links Between Gender and Poverty

Naila Kabeer

Article first published July 1997, IDSB28.3

Beyond the Rhetoric of Choice: Promoting Women's Economic Empowerment in Developed Countries

Claartje J. Vinkenburg

Article first published July 2015, IDSB46.4

Family, Households and Women's Empowerment in Bahia, Brazil, Through the Generations: Continuities or Change?

Cecilia M.B. Sardenberg

Article first published March 2010, IDSB41.2

Introduction: Quotas - Add Women and Stir?

Mariz Tadros Article first published September 2010, IDSB41.5

Women's Voices, Work and Bodily Integrity in Pre-Conflict, Conflict and Post-Conflict Reconstruction Processes in Sierra Leone

Hussainatu J. Abdullah, Aisha F. Ibrahim and Jamesina King

Article first published March 2010, IDSB41.2

Beyond the Mantra of Empowerment: Time to Return to Poverty, Violence and Struggle Uma Chakravarti

Article first published December 2008, IDSB39.6

Gender Equality in the Post-2015 Development Agenda: Lessons from the MDGs

Gita Sen

Article first published September 2013, IDSB44.5-6

Introduction: Negotiating Empowerment

Andrea Cornwall and Jenny Edwards

Article first published March 2010, IDSB41.2 


\title{
Beyond the Rhetoric of Choice: Promoting Women's Economic Empowerment in Developed Countries
}

\author{
Claartje J. Vinkenburg
}

\begin{abstract}
In preparing for the 20-year review of the Beijing Platform for Action on women's economic empowerment, both formal policy documents and media coverage in developed countries such as the Netherlands resonate with the rhetoric of choice between work and care. In this article, my central argument is that framing the combination of work and care as a matter of personal choice stands in the way of economically empowering women. To promote sustainability in combining career and care, we need to expose, challenge and bend underlying norms about gender roles. For policymakers to take responsibility in the economic empowerment of women, both policy documents and media coverage should promote win-win instead of zero sum solutions in combining work and care, for both men and women.
\end{abstract}

\section{Introduction}

In the Beijing Declaration and Platform for Action (BPfA), the resolution adopted by the UN at the Fourth World Conference on Women in 1995, 'women and the economy' was identified as one of 12 critical areas. The United Nations Entity for Gender Equality and the Empowerment of Women, or UN Women, founded in 2010, has adopted women's economic empowerment as one of its four priority areas. UN Women recently helped establish the Knowledge Gateway for Women's Economic Empowerment (EmpowerWomen.org), which is an open global platform that promotes collaboration, learning and innovation to advance women's economic empowerment. In the BPfA, various strategic objectives were formulated to promote women's economic empowerment through equal rights, opportunities, and access to economic resources. One of these objectives refers to the harmonisation of work and care responsibilities for women and men. This strategic objective is tied to the (implicit) assumption that women's economic empowerment is typically hindered by their larger share in care responsibilities for dependent children and extended family members compared to men.

As is evident from various policy documents, economic independence has been as a central element of policies towards gender equality and the empowerment of women in many developed countries, including the Netherlands. However, the dominant and normative rhetoric of choice between work and care in the public debate in such countries stands in the way of women's economic empowerment. In this article, I draw on documentation from the Netherlands' preparation for the 20-year review of the BPfA to posit that in framing the combination of work and care as a matter of personal choice, and by effectively leaving such issues to the private sphere, policymakers wash their hands of their responsibility of setting and meeting goals for women's economic empowerment.

In the Netherlands, government policymakers appear to have become complacent when it comes to the economic empowerment of women. This may be because of relative wealth, because women's care responsibilities are viewed as largely incompatible with full economic participation, and because previous initiatives to promote women's labour participation and economic independence failed to achieve the predefined goals. The same holds for many other developed countries, even if circumstances differ (see Barns and Preston (2002) for Australia, Ellingsæter (2009) for the Nordic 
states, and Lewis et al. (2008) for a comparative study across Europe). For progress in women's economic empowerment in such settings, of which the Netherlands is the example given here, a host of different actions has been suggested, implemented and - often - discarded as ineffective. A recalibration of the way government policymakers communicate about women, men, and their roles in society is needed in order to promote a cross-fertilisation between women's economic empowerment and sustainably combining work and care. Some have argued that we need to look at the social dimensions of constraint, as well as the cultural limits of 'choice', in exploring pathways to women's economic empowerment (Cornwall and Edwards 2010).

In this article I am not arguing for or against philosophical positions on free will and determinism. I am not trying to downplay the importance of the freedom of choice, and I do not intend to prescribe how women and men should make decisions in combining work and care. I am building on work on choice, norms and change to entice those who prepare policy documents and media representations on women's economic empowerment to move beyond the rhetoric of choice (van Engen, Vinkenburg and Dikkers 2012; Vinkenburg et al. 2012; Vinkenburg, van Engen and Peters 2015). Not only should we move beyond the rhetoric of choice, we should also change from talking about choosing between ('either or') to combining both ('and and') work and care.

\section{The choice rhetoric in preparations for Beijing}

The Netherlands' review of the implementation of the BPfA (Ministry of Education, Culture and Science 2014), states that:

The one-and-a-half income household model has replaced the breadwinner's model as the standard situation for a two-parent family. This usually manifests itself in a situation in which the man is the 'main breadwinner' and the woman 'earns a bit on the side'. [...] This situation is seen as a problem, among other reasons, due to the fact that one in three marriages fail and the financially dependent partner often is then forced to apply for social benefits. Studies and experience have shown that women tend to refrain from explicitly factoring in such a worst case scenario and therefore invest little in their future once they start to work part-time. A temporary choice to work fewer hours often turns out to have permanent consequences. Women start to work fewer hours when children arrive on the scene. Women regaining their economic independence once the children grow up happens much less often in the Netherlands than in other countries (2014: 54).

At the same time, the Netherlands' sixth periodic report to the UN Commission on the Status of Women, states that:

Emancipation is a process that cannot be forced on individuals. Freedom of choice is an important principle underpinning policy. The government prefers to use persuasion, by pointing to the possible consequences if women make choices that do not contribute to their own empowerment... Women who then opt for greater independence by, for example, working longer hours, can count on the government's support (Netherlands Government 2014: 14).

According to the BPfA review (Ministry of Education, Culture and Science 2014), while goals for women's economic independence were first formulated in 1995, 'participation in the job market among women rose rapidly, but many women chose to work part-time in order to be able to combine care duties and work better. So labour participation did not always lead to economic independence' (2014: 12). Therefore, the 'current government cabinet has abandoned the quantitative objective for the economic self-reliance of women' (2014: 13). 'The task of ensuring the ease of combining work and family care is not solely the responsibility of government, but also (and particularly) the responsibility of employers and employees sitting around the negotiating table' (2014: 55). In failing to achieve its BPfA goals for the economic self-reliance of women, the Netherlands government, in true liberal rather than social-democratic tradition, shifts the responsibility for this failure away from the state to the individual and her negotiating skills.

\section{Freedom of choice?}

Freedom of choice is one of the pillars of the Netherlands government's gender equality policy. Lewis et al. (2008) states that the rhetoric of choice has become an important means for the state to negotiate societal tensions inherent to the reconciliation of work and care. States operate as choice-promoting institutions (Olson 2002), supporting certain choices over others. However, according to Olson:

Choice has been used to draw an ideological line between public and private life that is highly problematic for women... Private life, 
in this construction, is a protected realm of unencumbered choice that contrasts with the compromises inherent in public, political life. In such a scheme, arrangements about the distribution of domestic labor and resources are 'private' and cannot be second-guessed by others (2002: 388).

\section{Ellingsæter (2009) explains how changing} employment patterns among women reflect changes in the societal context of people's choices. Political, economic and cultural opportunities and constraints shape aspirations and expectations. In a critical reflection on preference theory (see Hakim 2003), McRae (2003) argues that in Hakim's work the impact of situational and structural constraints on women's choices is insufficiently taken into account. Women do not have unfettered choices about how they wish to live because there are major constraints limiting or forcing their choices. 'At best, women's employment behaviour is a reflection of their historically available opportunities and constraints' (McDonald, Bradley and Guthrie 2006: 472). True freedom of choice is thus an illusion.

The choice rhetoric is not only dominant in policy papers, but also in media representations of how women and men combine work and care (Stephens and Levine 2011). Williams and Bornstein (2007) give an overview of the choice rhetoric in the popular press in the USA. Most recently, the Netherlands' media coverage of the 2015 monitoring report on women in executive positions resonates with choice for part-time work as the main cause of limited progress (Financieel Dagblad 2015). Also women themselves when asked to explain their situation commonly fall back on the rhetoric of choice, which reflects 'the culturally pervasive discourse of mothers', not fathers', ability to choose whether to participate in paid work at all' (Webber and Williams 2008: 755). According to Stone (2013), a focus on individual women and their 'choices' and preferences obscures institutional limits and barriers, as well as costs borne by women who 'opt out' or 'opt in-between' (Grant-Vallone and Ensher 2011).

Gender roles are increasingly viewed as an important factor in work-family decision-making (Andringa, Nieuwenhuis and van Gerven 2015). Injunctive and gendered norms about breadwinners and caregivers bind our choices. While often implicit, they are confirmed by the structural design of our society, and continuously reproduced by the media. To complicate matters further, almost every public debate and personal conversation about combining work and care is infused by pervasive norms about the social roles of men and women. Norms thus effectively serve as a straitjacket that force men and women into certain behaviours, and limit their freedom of choice. Those who step outside the norm can expect questions, raised eyebrows, and perhaps even discrimination. The impact of societal norms on decision-making and behaviour through processes of socialisation, internalisation and normalisation is well described (Evans and Diekman 2009). Paradoxically, the normative nature of norms is rarely recognised: 'Gender norms function as an unseen, unthematised background for people's choices' (Olson 2002: 395). Not only are these norms dominant in determining both our decisions and their short and long-term consequences, but the impact of these norms is exacerbated by the rhetoric of personal choice. If every decision in combining work and care is framed as something that is up to the individual, it becomes increasingly difficult to forge systemic change.

\section{Bending norms}

As norms based on gender roles underlie decisionmaking and behaviour in combining work and care, women's economic empowerment can only be achieved by critically re-examining such norms and their impact. The question, in looking beyond the rhetoric of choice, is how gendered norms and matching structural factors that play a determinative role in shaping decision-making can be uncovered, exposed, and changed. Olson (2002), in a critical analysis of policy changes in Sweden, develops six ways of using cultural agency to renegotiate gender norms. I propose that instead of framing decisions surrounding work and care as choice, we should focus on the critical conditions needed for effectively combining work and care. One of these conditions will undoubtedly pertain to high-quality low-cost care for those who need it as a basic provision. Another crucial condition is true flexibility in place and time of work, without negative sanctions. But most importantly, policymakers and media representatives should start talking and writing differently about combining work and care, and thus challenge and bend norms. The combination of work and care should be framed as 'and and' rather than 'either or'. Work and care instead of work or care. In doing so, women can be economically empowered, while simultaneously improving opportunities for giving and receiving care.

Policy changes affect decision-making, and may ultimately lead to changes in norms and gender roles (Sjöberg 2004). This implies that norms are 
not set in stone, and that policy changes can result in sustainable societal outcomes such as women's economic empowerment, more wealth, higher fertility, and improved wellbeing of all who work and all who need care.

In conclusion, both policy documents and media coverage in developed countries in discussions on

\section{References}

Andringa, W.; Nieuwenhuis, R. and van Gerven, M. (2015) 'Women's Working Hours: The Interplay between Gender Role Attitudes, Motherhood, and Public Childcare Support in 23 European Countries', International Fournal of Sociology and Social Policy 35: 11-12

Barns, A. and Preston, A. (2002) 'Women, Work and Welfare: Globalisation, Labour Market Reform and the Rhetoric of Choice', Australian Feminist Law fournal 17: 17-32

Cornwall, A. and Edwards, J. (2010) 'Introduction: Negotiating Empowerment', IDS Bulletin 41.2: $1-9$

Ellingsæter, A.L. (2009) 'Leave Policy in the Nordic Welfare States: A "Recipe" for High Employment/High Fertility?', Community, Work and Family 12.1: 1-19

Evans, C.D. and Diekman, A.B. (2009) 'On Motivated Role Selection: Gender Beliefs, Distant Goals, and Career Interest', Psychology of Women Quarterly 33.2: 235-49

Financieel Dagblad (2015) 'Slow Progress in Number of Women at Executive Levels', https://fd.nl/economie-politiek/1105268/ aantal-vrouwen-in-bedrijfstop-groeit-langzaam, 26 May (accessed 26 May 2015)

Grant-Vallone, E.J. and Ensher, E.A. (2011) 'Opting in Between: Strategies Used by Professional Women with Children to Balance Work and Family', Fournal of Career Development 38.4: 331-48

Hakim, C. (2003) 'Public Morality versus Personal Choice: The Failure of Social Attitude Surveys', British Fournal of Sociology 54.3: 339-45

Lewis, J.; Knijn, T.; Martin, C. and Ostner, I. (2008) 'Patterns of Development in Work/Family Reconciliation Policies for Parents in France, Germany, the Netherlands, and the UK in the 2000s', Social Politics: International Studies in Gender, State and Society 15.3: 261-86

McDonald, P.K.; Bradley, L.M. and Guthrie, D. (2006) 'Challenging the Rhetoric of Choice in Maternal Labour-Force Participation: Preferred versus Contracted Hours', Gender, Work, and Organization 13.5: 470-91 efforts to empower women economically should refrain from the rhetoric of choice, and should promote win-win instead of zero sum solutions in combining work and care. By doing so, the Netherlands' government, especially, can show its willingness and ability to take responsibility in meeting the strategic objectives of the BPfA in terms of women's economic empowerment.

McRae, S. (2003) 'Choice and Constraints in Mother's Employment Careers: McRae Replies to Hakim', British Fournal of Sociology 54.4: 585-92

Ministry of Education, Culture and Science (2014) The Netherlands Review Report of the Implementation of the Beijing Declaration and Platform for Action 2014, www.tweedekamer.nl/kamerstukken/ detail id $=2014$ D $38532 \&$ did $=2014$ D 38532 (accessed 10 February 2015)

Netherlands Government (2014) The Netherlands Sixth Periodic Report of the Implementation of the International Convention on the Elimination of all Forms of Discrimination against Women 2014, www.tweedekamer.nl/kamerstukken/ detail id=2014D38529\&did=2014D38529_ (accessed 10 February 2015)

Olson, K. (2002) 'Recognizing Gender, Redistributing Labor', Social Politics: International Studies in Gender, State and Society 9.3: 380-410 Sjöberg, O. (2004) 'The Role of Family Policy Institutions in Explaining Gender-Role Attitudes: A Comparative Multilevel Analysis of Thirteen Industrialized Countries', Fournal of European Social Policy 14.2: 107-23

Stephens, N.M. and Levine, C.S. (2011) 'Opting Out or Denying Discrimination? How the Framework of Free Choice in American Society Influences Perceptions of Gender Inequality', Psychological Science 22.10: 1231-6

Stone, P. (2013) “"Opting Out”: Challenging Stereotypes and Creating Real Options for Women in the Professions', paper presented at the Gender and Work: Challenging Conventional Wisdom symposium, Harvard Business School, Cambridge MA, 28 February-1 March, www.hbs.edu/faculty/conferences/2013-w50research-symposium/Pages/symposium-essays.aspx (accessed 23 June 2013)

Van Engen, M.L.; Vinkenburg, C.J. and Dikkers, J.S.E. (2012) 'Sustainability in Combining Career and Care: Challenging Normative Beliefs about Parenting', Journal of Social Issues 68.4: 645-64 Vinkenburg, C.J.; van Engen, M.L. and Peters, P. (2015) 'Promoting New Norms and True Flexibility: Sustainability in Combining Career and Care', in A. De Vos and B.I.J.M. Van der 
Heijden (eds), Handbook of Research on Sustainable Careers, London: Edward Elgar

Vinkenburg, C.J.; van Engen, M.L.; Coffeng, J. and Dikkers, J.S.E. (2012) 'Bias in Employment Decisions about Mothers and Fathers: The (Dis) Advantages of Sharing Care Responsibilities', Journal of Social Issues 68.4: 725-41

Webber, G. and Williams, C. (2008) 'Mothers in

"Good" and "Bad" Part-time Jobs', Gender and Society 22.6: 752-77
Williams, J.C. and Bornstein, S. (2007) 'The Evolution of "FReD": Family Responsibilities Discrimination and Developments in the Law of Stereotyping and Implicit Bias', Hastings Law fournal 59: 1311-58 